\title{
ACUERDO COMERCIAL MULTIPARTES Y SU INCIDENCIA EN LAS EXPORTACIONES DE ATÚN AL MERCADO ITALIANO
}

\author{
Jeyca Pamela Lozano Méndez ${ }^{1}$ \\ María De Los Ángeles Andrade Ortega ${ }^{2}$ \\ Universidad Laica Vicente Rocafuerte de Guayaquil. Facultad de Administración. Carrera de Comercio Exterior \\ jlozanome@ulvr.edu.ec \\ mandrade@ulvr.edu.ec
}

\begin{abstract}
Para citar este artículo puede utilizar el siguiente formato:
Jeyca Pamela Lozano Méndez y María De Los Ángeles Andrade Ortega: "Acuerdo comercial multipartes y su incidencia en las exportaciones de atún al mercado italiano", Revista Observatorio de la Economía Latinomericana (Vol 19, № 2, pp. 31-51, febrero 2021). En línea:

https://www.eumed.net/es/revistas/economia-latinoamericana/oel-febrero21/acuerdo-comercialexportaciones
\end{abstract}

\section{RESUMEN}

El presente estudio se ha estructurado sobre las bases del Acuerdo Comercial Multipartes entre la Unión Europea y la Comunidad Andina de Naciones, debido a que representa uno de los mayores mercados del mundo para la región latinoamericana e internacional. El sector exportador de atún del Ecuador representa uno de los principales rubros de la economía nacional para el desarrollo económico - productivo, razón por lo que, este estudio busca analizar los beneficios que brinda el Acuerdo Comercial Multipartes para el incremento y fortalecimiento de este importante sector, destinado a la comercialización en el mercado de la República Italiana. El tipo de investigación es exploratoria y descriptiva y el enfoque de la investigación es cualitativo - cuantitativo, con el objetivo de analizar la expansión y efectos de la industria comercial de pesca de atún en las exportaciones del Ecuador, período 2017 - 2019, dando como resultados que desde la vigencia del Acuerdo Comercial Multipartes, el 1 de enero de 2017, el sector exportador atunero sí se ha beneficiado de su implementación en el mercado nacional, debido a que ha abierto las puertas a uno de los mercados más grandes del mundo y que los representantes del sector exportador atunero del Ecuador consideran que el posicionamiento comercial de la exportación de atún debe ser fortalecido a través

1 Estudiante de la Carrera de ingeniería en Comercio Exterior de la Universidad Laica Vicente Rocafuerte de Guayaquil. Ejecutivo de cuentas, Grupo Gando COMEXTGANDO S.A., 7 años de experiencia.

2 Estudiante de la Carrera de ingeniería en Comercio Exterior de la Universidad Laica Vicente Rocafuerte de Guayaquil. 3 años de experiencia de Agente de Seguridad y 2 años de experiencia de Agente de Carga en Longport Aviation. 
de la Comunidad Andina de Naciones. La propuesta de la estrategia comercial para el sector atunero, se ha establecido sobre 6 objetivos estratégicos que buscan promover el mantenimiento y desarrollo de las exportaciones hacia el mercado italiano.

Palabras clave: Acuerdo Comercial Multipartes, Mercado italiano, Atún, Exportación

\section{MULTIPARTY TRADE AGREEMENT AND ITS IMPACT ON TUNA EXPORTS TO THE ITALIAN MARKET}

\section{ABSTRACT}

This study has been structure based on the Multiparty Trade Agreement between the European Union and the Andean Community of Nations, since it represents one of the largest markets in the world for the Latin American and international region. The tuna export sector of Ecuador represents one of the main items of the national economy for economic and productive development, which is why this study seeks to analyze the benefits provided by the Multiparty Trade Agreement for the increase and strengthening of this important sector, destined to the commercialization in the market of the Italian Republic. The type of research is exploratory and descriptive and the focus of the research is qualitative - quantitative, with the aim of analyzing the expansion and effects of the commercial tuna fishing industry on exports from Ecuador, period 2017-2019. Giving results that since the Multiparty Trade Agreement came into force, on January 1, 2017, the tuna export sector has benefited from its implementation in the national market, because it has opened the doors to one of the largest markets in the world. In addition, that the representatives of the Ecuadorian tuna export sector consider that the commercial positioning of tuna exports should be strengthened through the Andean Community of Nations. The proposed commercial strategy for the tuna sector has been established on 6 strategic objectives that seek to promote the maintenance and development of exports to the Italian market

Keywords: Multiparty Trade Agreement, Italian Market, Tuna, Export

\section{INTRODUCCIÓN}

La importancia del desarrollo de las relaciones internacionales constituye el elemento fundamental de la globalización para el intercambio de ideas, productos, bienes y servicios que representan el escenario apropiado para la integración entre países (Baquerizo, Barbery, \& Bocca, 2018). Por ello, el comercio internacional constituye una herramienta de productividad que acerca a los países en complementariedad de los productos y servicios que requieren en sus sociedades, promoviendo el desarrollo laboral, económico, financiero y de productividad, especialmente para los países en vías de desarrollo como los de América Latina y específicamente Ecuador.

Es así, que el presente estudio se ha estructurado sobre las bases del Acuerdo Comercial Multipartes entre la Unión Europea y la Comunidad Andina de Naciones, debido a que representa uno de los mayores mercados del mundo para la región latinoamericana e internacional, en fortalecimiento de sus intereses económicos, intercambiando todo tipo de productos e incidiendo en 
el desarrollo de los sectores empresariales, especialmente de pequeños y medianos empresarios y microempresarios, que representan gran parte del segmento competitivo de la industria ecuatoriana. Por tanto, la incidencia de los acuerdos comerciales tiene gran impacto en el crecimiento de los países, razón por lo que, en la última década se han fomentado para un desarrollo comercial equitativo y complementario, específicamente entre Ecuador y el mercado italiano, dentro de la zona euro.

\section{Planteamiento del problema}

Sobre tal argumento que plantea el problema de investigación, se define el escenario donde el crecimiento de las exportaciones puede influir indirectamente en el desarrollo económico mediante la asignación eficiente de recursos, una mayor utilización de la capacidad, la explotación de economías de escala y el estímulo de la mejora tecnológica resultante de la competencia en el mercado exterior que además, es promovido y fortalecido mediante acuerdos comerciales que constituyen los determinantes del crecimiento económico en un mercado internacional integrado. Sin embargo, la relación entre las importaciones y el crecimiento económico tiende a ser más complicada, debido a los efectos de la sustitución de importaciones, que determina un elemento que puede generar falencias en la competitividad de un mercado, aun cuando exista un Acuerdo Comercial.

Este es el elemento central del planteamiento del problema, debido a que desde el 1 de enero de 2017, entró en vigencia el Acuerdo Comercial Multipartes entre Ecuador y la Unión Europea (UE), eliminando barreras arancelarias (0\%) para los productos nacionales; por lo que, tanto para productos agrícolas $(99,7 \%)$, como para productos industriales (100\%), se eliminó aranceles que constituían un escenario de desventaja en un mundo de competitividad productiva para el intercambio comercial internacional (Ministerio de Comercio Exterior de la República del Ecuador, 2017). Es por ello, que los resultados que se esperaban del Acuerdo Comercial Multipartes eran alentadores para promover el desarrollo económico y crecimiento del mercado entre ambos sectores del comercio internacional, esperando un incremento anual del $0,10 \%$ del Producto Interno Bruto (PIB); además de un $0,15 \%$ en el consumo y un $0,13 \%$ en la inversión, que asegure la liberalización de la oferta exportable (Comisión Económica para América Latina y el Caribe, 2019).

La UE es el principal destino de las exportaciones de atún ecuatoriano (25\%), y entre ellos el 9,1\% (2017), va destinado al mercado italiano, como uno de los mayores del mundo para ser aprovechados por el Ecuador (Banco Central del Ecuador, 2020). Es así, que, los productos principales que se beneficiarían de este acuerdo son productos representativos de la exportación nacional, entre ellos, el sector pesquero, el atún es el más importante. En consecuencia, el atún es el tercer principal producto de exportación del Ecuador, con cifras que superan los US $\$ 1,600$ millones de dólares anuales y representa 500.000 toneladas de pescado fresco y enlatado, lo cual equivale al $11 \%$ de las exportaciones nacionales, aportando al desarrollo productivo y económico del país y promoviendo crecimiento en todos los sectores de la sociedad (Ministerio de Producción, Comercio Exterior, Inversiones y Pesca, 2019).

Cabe notar que la afectación por el actual Estado de Excepción declarado en Decreto Presidencial 1017 en el mes de marzo, ha afectado aún más la situación comercial entre ambos países, considerando, además, que Italia también atraviesa un difícil momento por la pandemia por 
Covid-19, que de hecho llevó al país europeo a ser uno de los más afectados del mundo (Decreto Ejecutivo No. 1017, 2020). Es por ello, que el problema del decrecimiento de las exportaciones de atún al mercado italiano, aún con la vigencia del Acuerdo Comercial Multipartes, representa una afectación directa a los intereses económicos y productivos nacionales en la promoción del crecimiento de las exportaciones, que tiene un papel complementario potencial para estimular el desempeño económico general a través del comercio internacional.

\section{Objetivos de la investigación}

\section{Objetivo general}

Analizar los beneficios que brinda Acuerdo Comercial Multipartes para el incremento y fortalecimiento del sector exportador de atún hacia el mercado italiano.

\section{Objetivos específicos}

- Recopilar información de las causas del descenso de las exportaciones de atún a la Unión Europea, específicamente al mercado italiano.

- Conocer las características, ventajas, desventajas y experiencias que conlleva el Acuerdo Comercial Multipartes para el sector atunero nacional.

- Proponer una estrategia comercial para el sector exportador atunero que promueva el mantenimiento y desarrollo de las exportaciones hacia el mercado italiano.

\section{Justificación}

El presente estudio se justifica para conocer los resultados presentados por el Gobierno nacional en el marco del Acuerdo Comercial Multipartes, Ecuador - Unión Europea (específicamente en relación al mercado italiano), exponiendo el desarrollo económico y comercial que representa para el país a partir de la evaluación del informe del Banco Central del Ecuador para la Balanza Comercial desde que entró en vigencia la relación comercial bilateral libre de aranceles, específicamente enfocado en el sector atunero, como uno de los principales sectores exportadores del Ecuador en aporte al PIB (4,7\%), y sobre lo cual, el Estado ha mantenido la perspectiva de desarrollo económico - productivo, a través de la promoción de crecimiento del sector exportador nacional, como uno de los elementos fundamentales para la generación de empleo, productividad y desarrollo económico (Banco Central del Ecuador, 2020).

Es por esto, que, a pesar de una tendencia general al alza en todo el mundo en la diversificación de las exportaciones entre los países en desarrollo, los resultados del informe de comercio exterior representados en los datos del intercambio bilateral, muestra que la concentración en las exportaciones ecuatorianas en realidad decreció, especialmente en los años 2018 y 2019, (acentuándose a niveles críticos en los meses enero - mayo de 2020) lo cual expone una situación preocupante que debe ser abordada desde la descripción económica, productiva y comercial actual, considerando al llamado de atención de la UE (Tarjeta amarilla) sobre la pesca nacional, para lo cual se desarrolla este estudio.

Por tanto, la presente investigación se adecua al acervo del conocimiento comercial, enfocado en las exportaciones nacionales, que han sido impulsadas a través de las políticas públicas para el fomento del comercio exterior y de la diversificación de la matriz productiva, en aprovechamiento de 
las ventajas que brinda el Acuerdo Comercial Multipartes para la introducción de productos de reconocimiento mundial, como el atún ecuatoriano al mercado común europeo, por lo que constituye un importante aporte al desarrollo económico y productivo nacional.

\section{Marco teórico}

\section{Fundamentación teórica}

\section{Industria 4.0 en el comercio internacional}

El término Industria 4.0 se utilizó por primera vez en la feria industrial alemana de 2011 Hannover; este término, también conocido como la cuarta revolución industrial, se centró en cómo integrar nuevas tecnologías y digitalizarlas para lograr ventajas productivas y fortalecer el comercio nacional e internacional desde sus inicios (Basco, Beliz, Coatz, \& Garnero, 2018).

Junto con la Industria 4.0, la estructura del comercio exterior está cambiando, en consecución con los desarrollos, las exportaciones e importaciones se realizan no solo con el comercio de bienes sino también con el comercio de datos. Estos datos incluyen conceptos como libros electrónicos, políticas comerciales, fundamentos de productos normalizados, como una ventaja de la reducción de restricciones a partir de esta tecnología para prestación de servicios innovadores en el mercado internacional (Dragún, Ernst, Díaz, \& Kübler, 2020). Por tanto, las ventajas de la industria 4.0 y la elaboración de los productos de una manera más innovadora afectan a los países que han hecho comercio entre ellos, y benefician su desarrollo en todos los niveles.

\section{Problemas actuales de los países en desarrollo}

Los problemas actuales de los países en desarrollo se determinan a partir de las políticas macroeconómicas y liberalización comercial con que cuentan, por ello, se espera que las políticas de liberalización del comercio a largo plazo cambien los recursos hacia el comercio internacional, especialmente exportable y lejos de los cambios externos sustitutos de importación (Savignat, 2015). Por tanto, el alcance de una política exitosa de liberalización del comercio depende de políticas macroeconómicas y otras políticas internas complementarias que logren y mantengan la estabilidad en la economía nacional e internacional y promuevan la reasignación de recursos en respuesta a la reforma económica y comercial que implemente el país para adherirse a la economía y comercio globalizados (Rapoport \& Guiñazú, 2016).

\section{Comercio exterior de los países en desarrollo: América Latina}

El comercio exterior, visto desde la visión comercial de los países en desarrollo de América Latina, constituye una previsión emergente de economía integrada y globalizada, que convencionalmente proporciona un tipo de cambio realista se considera vital para la introducción exitosa de la reforma comercial en la evolución del mercado internacional de los países en desarrollo hacia una economía globalizada (Hidalgo, 2018). Siendo así, en países con monedas distintas, el tipo de cambio real debería ayudar a garantizar el equilibrio en la balanza de pagos y en los mercados internos y debería ser compatible con el crecimiento de la comercialización y la producción de la oferta al mercado (Caballero, Bacaria, \& Tur, 2016). Por tal razón, una moneda sobrevaluada tiene un sesgo antiexportador en el sentido de que grava indirectamente los productos exportables al 
tiempo que favorece los no comerciables e importables en una economía y mercado globalizados, donde las políticas económicas y comerciales deben ser consecuentes con el desarrollo e integración en bloques comerciales para mantener la demanda del mercado en base a una oferta sostenible. Una devaluación real mejora los incentivos para las industrias de exportación y la producción de sustitutos de importación, especialmente en mercados tan competitivos como el mercado de la pesca internacional, donde el atún es considerado un producto de alta demanda internacional (Páez, 2018).

\section{Restricciones comerciales de exportaciones en América Latina}

Según el informe de Global Trade Alert (2020) del Centro de Investigación en Política Económica del Reino Unido, los países de América Latina son de los que menos restricciones económicas en medidas proteccionistas imponen a su comercio exterior. Por ello, las restricciones que surgen del comercio internacional se dan principalmente de los más grandes mercados mundiales, donde la Unión Europea, Estados Unidos y China son los que más imponen medidas restrictivas al momento de comercializar productos en el mercado globalizado con los países en vías de desarrollo (Ruano, 2018). Por tal razón, dichas restricciones se posicionan sobre la línea de proteccionismo que generalmente se instituye en mercados localizados como en países emergentes, donde la inestabilidad política y económica lleva al sector exportador a mantener un estado de variabilidad en relación con sus exportaciones sobre la oferta y demanda (Martín, 2016).

Sobre ello, el mercado internacional exige diferentes secuencias de reforma, donde la eliminación de las restricciones a las exportaciones puede ser relevante en algunos casos, la reducción de las restricciones a la exportación e importación simultáneamente en otros y una reducción de la protección aún para mercado emergentes de países en desarrollo que representa una perspectiva de crecimiento económico, social y de mercado (Fondo Monetario Internacional, 2016). Con respecto a la secuencia de las medidas de liberalización, la literatura de la economía y el comercio internacional, sugieren ciertas reglas generales que establecen que los aspectos de la liberalización del comercio que involucran solo costos de ajuste que pueden implementarse tan rápido como lo permitan los factores técnicos (Villegas, Montesdeoca, \& Conde, 2018). Es así, que, las medidas adoptadas en América Latina representan de las menos restrictivas en el mundo, y mercados de la Unión Europea como el de la República Italiana representan de los más restrictivos con 225 medidas restrictivas, frente a las 34 de Ecuador, tal como se demuestra la tabla 1:

\section{Tabla 1}

Restricciones comerciales

\begin{tabular}{lll}
\hline País & Medidas proteccionistas & Medidas Liberizadoras \\
\hline Estados Unidos & 399 & 65 \\
Rusia & 481 & 23 \\
Italia & 225 & 14 \\
España & 211 & 16 \\
China & 190 & 7 \\
América Latina & & \\
Argentina & 335 & 37 \\
Brasil & 266 & 213 \\
México & 88 & 21 \\
\hline
\end{tabular}




\begin{tabular}{lll}
\hline Colombia & 60 & 33 \\
Venezuela & 55 & 46 \\
Uruguay & 54 & 28 \\
Ecuador & 34 & 23 \\
Perú & 31 & 10 \\
Paraguay & 22 & 20 \\
Bolivia & 19 & 24 \\
Chile & 16 & 8 \\
Panamá & 5 & 1 \\
Costa Rica & 6 & 2
\end{tabular}

Nota. Tabla 1 tomado del Boletín Estadístico de Comercio Exterior en América Latina y el Caribe por la Comisión Económica para América Latina y el Caribe (2019). Obra de dominio público.

Por tanto, las medidas restrictivas del mercado internacional son más bajas en los países de América Latina en relación a los demás mercados de países desarrollados en el mundo, por lo cual, el orden de secuencia, según ello, es pasar de eliminar el impedimento a la exportación, a reemplazar la restricción cuantitativa a la importación por el mecanismo de precios y finalmente a reducir los niveles de protección y los diferenciales del mercado (Rosales \& Herreros, 2017).

\section{Comercio bilateral entre la Unión Europea y Ecuador}

La relación del comercio bilateral entre Ecuador y la Unión Europea (UE) marca su punto de partida en la importancia del contexto histórico de los lazos comerciales, económicos, políticos y sociales que unen y vinculan a Europa con América Latina y el país, de manera específica (Rosales \& Guerrero, 2019). El objetivo de esta relación es crear una zona de libre comercio, especialmente entre la Comunidad Andina de Naciones (CAN) y la UE, por lo que se han desarrollado desde la década de los 80, conversaciones bilaterales que han desembocado en el presente Acuerdo Comercial Multipartes vigente desde 2017 (Tamayo \& Vásquez, 2019). Al igual que con otros acuerdos comerciales, este acuerdo establece que se promoverá el progreso económico y social, teniendo en cuenta el principio de desarrollo sostenible y los requisitos de protección ambiental. La parte más detallada es la de cooperación comercial bilateral que cubre áreas como transporte, pesca, protección de inversiones, telecomunicaciones, así como cooperación aduanera, agrícola, estadística, tecnológica y educativa, etc. (Rivadeneira, Iturriaga, \& Andrade, 2019).

\section{Acuerdo Comercial Multipartes y sector exportador ecuatoriano}

El Acuerdo Comercial Multipartes, específicamente entre Ecuador y la Unión Europea ha presentado resultados beneficiosos para la economía nacional, que incrementó en 2017 sus exportaciones hacia el bloque europeo en $12 \%$, esto representa aproximadamente US $\$ 300$ millones para la variedad de productos exportables del país (Banco Central del Ecuador, 2020). En relación con ello, el impacto en la economía ecuatoriana fue mencionada por el Departamento de Unidad para América Latina de la Dirección General de Comercio de la Unión Europea, como una herramienta de crecimiento y productividad entre las dos partes, puesto que sus beneficios se podrán cuantificar a corto, mediano y largo plazo para las dos economías, aportando además en el país para mercado abierto de 27 países del bloque comunitario (Jürgensen, 2019). En contraste con ello, dichos datos de perspectiva para el intercambio comercial se consideraron negativos en el superávit de la balanza 
comercial de diciembre de 2019, que decreció en relación con 2016, 2017 y 2018, tal como se presenta en la figura 5 en la estimación económica de la balanza comercial nacional.

\section{Figura 1}

Comercio Exterior entre Ecuador y la Unión Europea (2016 - 2019)

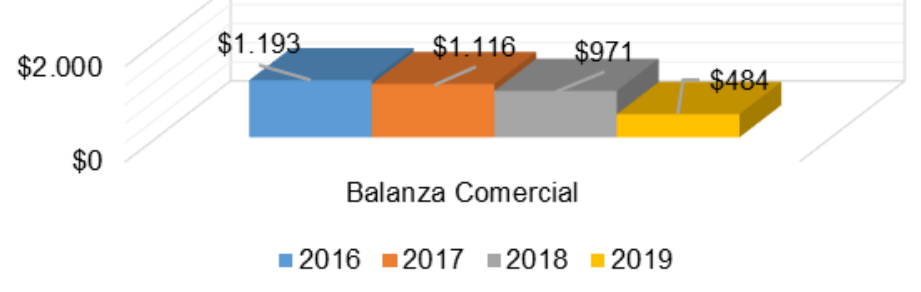

Nota. Figura 1 adaptado de datos del "boletín de Comercio Exterior entre Ecuador y la Unión Europea, Acuerdo Comercial Multipartes. Transición 2016 - 2017, 2018”, por Federación Ecuatoriana de Exportadores (2019). Obra de dominio público.

El descenso de la balanza comercial entre Ecuador y la Unión Europea manifiesta múltiples razones, las cuales se han constituido debido a factores internos y externos a la normativa y políticas públicas ecuatorianas, siendo una de las más sobresalientes en el descenso, las prácticas pesqueras del país, que han recibido sanciones por parte del bloque comunitario para el mantenimiento fluido del comercio del sector acuícola (especialmente del atún y productos derivados del atún) (Aguilar, Maldonado, \& Solorzano, 2019).

Las exportaciones de atún, específicamente de lomos de atún y conservas derivadas a la Unión Europea representaron US\$717,523 (millones de dólares americanos), que se mantuvieron por delante de todas las exportaciones de este mercado internacionalmente. Por tanto el Ecuador presentaba datos de exportaciones que ubicaban a la UE en el principal destino de las exportaciones de atún, lo cual se vio afectado debido a la sanción de Tarjeta amarilla que el bloque comunitario impuso al país y que a través de una reforma al entonces proyecto de Ley Orgánica de Pesca y Acuicultura ingresada al pleno de la Asamblea Nacional, se pretende complementar con el Plan de Acción para el sector pesquero para hacer frente a las sanciones derivadas de ello, que han descendido para 2019 hasta en un 5,6\% de la Balanza Comercial (Ley Orgánica para el Desarrollo de la Acuicultura y Pesca, 2020).

\section{Figura 2}

Exportaciones de lomos y conservas de atún $(2018$ - 2019) 


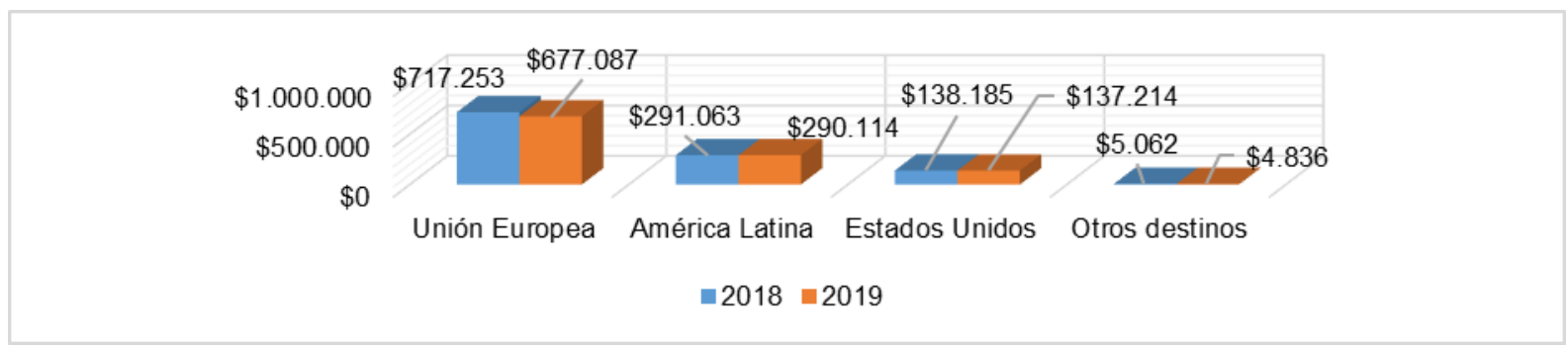

Nota. Figura 2 adaptado de información de Exportaciones de lomos y conservas de atún, por la Cámara Nacional de la Pesquería (2019). Obra de dominio público.

\section{Sector exportador atunero y mercado italiano}

Desde el inicio en 2017 de la vigencia del Acuerdo Comercial Multipartes entre Ecuador y la Unión Europea, Italia, se convirtió en el principal cliente de las exportaciones ecuatorianas, seguido de Alemania (Banco Central del Ecuador, 2020). Sobre ello, el atún (en pescado en estado natural y productos industriales derivados de atún) se ha posicionado como uno de los principales productos que el país exporta hacia Italia, considerando que el $63 \%$ de las exportaciones de atún tienen destino el bloque comunitario y de ello, el 9,1\% va destinado hacia el mercado italiano, especialmente de atún aleta amarilla, que constituye la variedad de atún más demandado en este país europeo (Ministerio de Comercio Exterior de la República del Ecuador, 2017).

Por tanto, es claro que, el sector exportador atunero representa un importante segmento económico - comercial para el país, e incide de manera directa sobre el desempeño y desarrollo productivo que se genera del Acuerdo Comercial Multipartes, por ello, debe ser observado desde un entorno de competitividad bilateral, considerando además la importancia del mercado español que también ofrece este producto dentro de la Unión Europea y goza de mayores ventajas comerciales.

\section{Figura 3}

Exportaciones de atún al mercado italiano

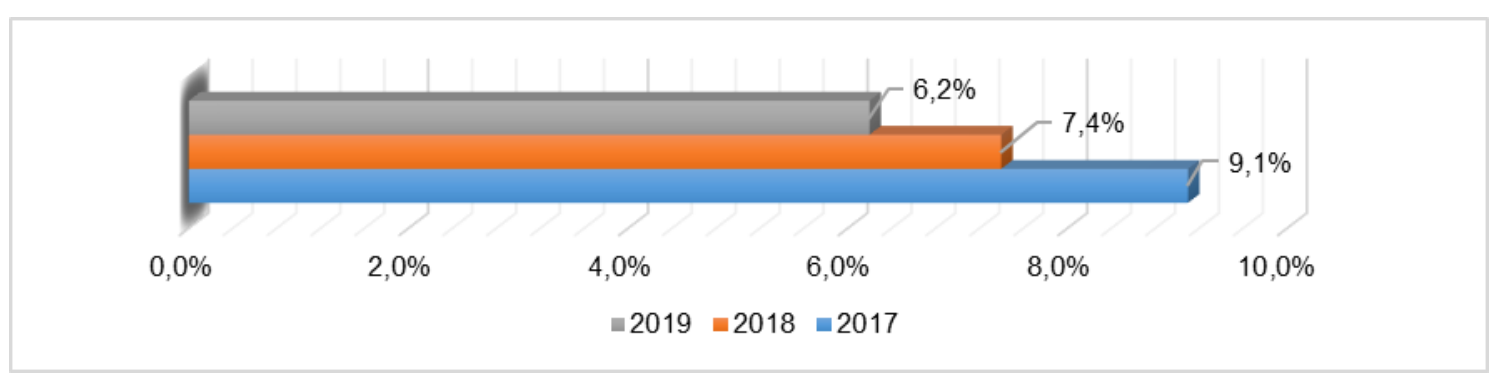

Nota. Figura 3 adaptado de la Balanza comercial del Ecuador, Sector Exportador de Atún: 2017 2019 Ecuador - Unión Europea (Mercado Italiano), por el Banco Central del Ecuador (2020). Obra de dominio público.

La competitividad del mercado de atún en la Unión Europea está liderada por el sector atunero de España, que representa el mayor competidor para Ecuador al interior del bloque comunitario. Por tanto, son observables los beneficios que goza el sector productivo atunero español dentro del bloque de los 27 países, ya que mantiene barreras comerciales en cero, lo que plantea un desafío para el Ecuador aun con la vigencia del Acuerdo Comercial Multipartes, razón por lo que, el 
mantenimiento de la calidad y normativa del producto ecuatoriano deben solventarse de acuerdo a los requerimientos de la UE en el marco del acuerdo comercial, y además con un valor agregado en calidad, precio y promoción en un mercado internacional como el italiano que necesita un producto de reconocimiento internacional y que además compita con la calidad y precio de un producto local como el español en el mercado europeo.

\section{Marco metodológico}

\section{Tipo de investigación}

El tipo de investigación es exploratoria y descriptiva; exploratoria, debido a que brinda la información necesaria, fundamentada en datos estadísticos oficiales del Estado para establecer los resultados obtenidos del intercambio comercial producto del Acuerdo Comercial Multipartes en el sector exportador atunero del Ecuador (Ruas, 2016). Además, es descriptiva debido a que describe el escenario actual vigente de este acuerdo y la incidencia que ha tenido en el sector objeto de estudio, a través de una investigación de campo que ayude a obtener la información necesaria de manera específica y con ello poder analizar los resultados en la economía y mercado nacional en relación con el mercado italiano y la balanza comercial que de ello se deriva.

\section{Enfoque de la investigación}

El enfoque de la investigación es cualitativo - cuantitativo, con el objetivo de analizar la expansión y efectos de la industria comercial de pesca de atún en las exportaciones del Ecuador, período 2017 - 2019, para obtener estos resultados que se formularán desde una revisión literaria y datos estadísticos, lo cual se contrastará y cuantificará a través del estudio. Por tanto, el enfoque de investigación presenta un escenario mixto que se ha estructurado en base a los resultados obtenidos del presente acuerdo entre el Ecuador y el mercado italiano, de manera específica, como uno de los más importante dentro de la zona euro. Con el desarrollo de este enfoque, se estudia la incidencia de manera directa que tiene el intercambio comercial bilateral, desde un entorno multipartes, debido a que involucra al bloque de la Comunidad Andina de Naciones, con ejecución directa para cada Estado, en la determinación de sus especificaciones acorde al mercado local.

\section{Técnicas e instrumentos de investigación}

La técnica de investigación es la encuesta y el instrumento es el cuestionario de preguntas de 10 interrogantes que se realizó en la Cámara Nacional de Pesquería (CNP) de la Ciudad de Guayaquil, a través de mailing (encuesta por correo electrónico), debido a la situación de pandemia por Covid19, razón por lo que, se han digitalizado las encuestas con el propósito de llegar a todos los involucrados en el estudio y así conocer su perspectiva de desarrollo sobre el Acuerdo Comercial Multipartes en incidencia del comercio internacional para las exportaciones de atún entre Ecuador y el mercado italiano. Con ello, también se buscó contrastar los datos con las estadísticas de exportaciones del sector atunero, que esta importante área de la economía ha presentado en el periodo 2017 - 2020 (enero - mayo) y cómo se ha desempeñado en el mercado internacional con este nuevo acuerdo multipartes. 


\section{Población y muestra}

La población para esta investigación esta direccionada hacia el sector exportador atunero, específicamente en la Cámara Nacional de Pesquería, desde donde se recolectarán datos de sus miembros, estimados en una población de 1,057 empresarios de este sector productivo, afiliados a la CNP, y sobre ello se procede a la aplicación de la formula estadística para el cálculo de la muestra (Cámara Nacional de Pesquería, 2019). A continuación, se detalla cada uno de los elementos que contiene la fórmula, con la finalidad de luego realizar su respectivo cálculo con un margen de error del $5 \%$, donde:

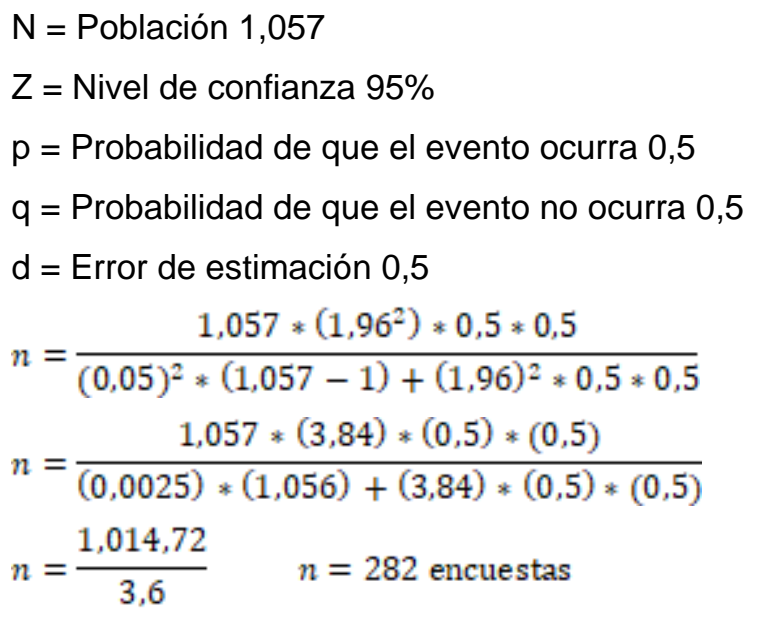

\section{Resultados de encuesta}

Los representantes del sector exportador atunero del Ecuador respondieron en un 62,42\% estar totalmente de acuerdo en que desde la vigencia el 1 de enero de 2017, el Acuerdo Comercial Multipartes ha traído beneficios a este importante sector de la economía, considerando que gradualmente liberalizó las barreras arancelarias, promoviendo mayor competitividad en la industria atunera hacia el mercado de la Unión Europea, específicamente para el desarrollo temático en el mercado italiano.

Los representantes del sector exportador atunero respondieron en un 37,58\% estar totalmente de acuerdo en que el Ecuador debe fortalecer su posición comercial desde el bloque de la Comunidad Andina de Naciones, frente a la Unión Europea, considerando que sobre el actual acuerdo la UE ha implementado medidas restrictivas para el sector pesquero ( $y$ atunero en inclusión), que vulneran los derechos comerciales del país frente al mercado comunitario, situación que podría ser minimizada si existiera una posición de bloque formalizada en el tratamiento comercial vigente.

El $45,39 \%$ de los representantes del sector exportador atunero, respondieron estar totalmente de acuerdo en que el Acuerdo Comercial Multipartes ha aportado ventajas competitivas en el comercio internacional, considerando que Ecuador posee una de las flotas pesqueras más grandes del mundo, lo cual fomenta el desarrollo competitivo y productivo de este sector de mercado y de la economía nacional, basado en la globalización e integración comercial con los países más desarrollados.

El $68,08 \%$ de los representantes del sector exportador atunero, han respondido estar totalmente de acuerdo en que las exportaciones hacia el mercado italiano deben ser promovidas y fortalecidas desde la cooperación del sector pesquero, en todas sus áreas, considerando el descenso que ha resultado $(5,6)$ en 2020 para este importante sector productivo, por lo que debe ser integrado dentro 
de las prioridades económicas de la política comercial del Ecuador, en coordinación con el sector privado - público, para fomentar el crecimiento coordinado desde el Estado hacia los mercados internacionales, especialmente hacia el mercado italiano como parte de la UE.

Las respuestas obtenidas son variadas en esta pregunta, debido a que los representantes del sector exportador atunero consideran en un $34,39 \%$ que sí se ha restado competitividad al sector productivo a partir de 2019 - 2020, tomando en cuenta las restricciones (tarjeta amarilla) que la UE impuso a Ecuador, ocasionando una afectación directa al sector pesquero, especialmente al sector atunero. El 30,49\% considera que se restó competitividad parcialmente, estimando que al existir un acuerdo comercial se puede fomentar el mejoramiento de las relaciones comerciales entre ambos bloques y con ello, incrementar las exportaciones del sector atunero ecuatoriano hacia el mercado italiano.

El $51,77 \%$ de los representantes del sector exportador pesquero, dijeron estar totalmente de acuerdo en que la legislación del Ecuador se adecue a las solicitudes de la Unión Europea sobre política pesquera, considerando que debido a dichas observaciones el bloque comunitario impuso restricciones a las exportaciones de pescado de manera general, afectando a las exportaciones atuneras en 2020. Por tal razón, la mayoría de los encuestados se pronunció favorable al cambio de legislación, considerando que la UE es de los más grandes socios comerciales en destino de exportaciones para este sector productivo.

Los representantes del sector exportador atunero han dicho estar en un $63,12 \%$ totalmente de acuerdo en implementar mesas de dialogo en el sector industrial productivo pesquero con el propósito de fomentar, motivar y promover el incremento de las exportaciones de su sector, considerando que la UE ha impuesto observaciones a la política comercial pesquera del Ecuador, por lo que, aunque ya están definidas las normas comerciales en el Acuerdo Comercial Multipartes, se pueden adherir mejoras que incrementen la confianza entre ambas partes y con ello, se fortalezcan las exportaciones que son fundamentales para el mantenimiento de la economía ecuatoriana.

El $69,85 \%$ de los representantes del sector exportador atunero ha dicho estar totalmente de acuerdo en que es beneficios que el país se integre en una negociación de bloque con la CAN para la protección de las aguas de zona económica exclusiva, considerando que continuamente son objeto de penetración por parte de flotas pesqueras internacionales que se introducen de manera ilegal en aguas de los Estados rivereños del pacifico sur de América Latina, por lo que, una política integral regional promovería mayor cuidado, protección y patrullaje de la zona, y con ello, la pesca comercial en la ZEE se ejecutaría de manera estructurada y adecuada a las normativas internacionales pesqueras.

El $34,75 \%$ de los representantes del sector exportador atunero, dijeron estar totalmente de acuerdo en que la industria 4.0 sea adherida como parte integral de los procesos de comercio internacional del sector exportador atunero, considerando que a través de ello se aporta con innovación y tecnificación de la productividad en el Ecuador. El 34,39\% dijo estar parcialmente de acuerdo, debido a que representan un sector más conservador de este sector productivo, considerando que sí están de acuerdo en innovar y tecnificar, pero en etapas específicas del proceso comercial, estimando que debe mantenerse el proceso como actualmente se realiza, situación que 
debe ir evolucionando en base a la integración de criterios de los representantes de este importante sector de la economía.

El $73,40 \%$, es decir, la gran mayoría de los representantes del sector exportador atunero, respondieron estar totalmente de acuerdo en la implementación de una estrategia integral comercial para su sector, en la construcción de una política comercial integral sectorial que promueva el mantenimiento y fortalecimiento de este importante sector productivo, desde las bases económicas representadas por microempresarios y pequeños y medianos empresarios que aportan al sector exportador atunero con toneladas de pesca anual para el desarrollo comercial internacional del Ecuador.

\section{Informe final}

\section{Estrategia comercial para sector exportador atunero}

\section{Objetivos de la estrategia comercial}

Sobre la base de los principios comerciales del Ecuador, se han desarrollado una serie de objetivos estratégicos clave para fomentar, fortalecer y promover la estrategia comercial:

a.Implementar la gestión para lograr recursos pesqueros nacionales sostenibles de acuerdo con los principios de sustentabilidad e incluyendo, cuando corresponda, la gestión de la pesca basada en el ecosistema,

b.Apoyar el crecimiento del sector privado en todas las etapas de la cadena de valor, incluida la producción pesquera, el valor agregado y las industrias de apoyo.

c.Garantizar atún inocuo, adecuados y de buena calidad para el consumo internacional (y nacional).

d.Reducir la exposición al riesgo a medio y largo plazo del sector de exportación atunero.

e.Transición a un enfoque de ordenación conjunta más participativo para la ordenación y el desarrollo de la pesca que:

i. Involucre a todos los interesados clave

ii. Reconozca al sector privado en la elaboración de un plan maestro de pesca, sobre beneficios que se derivan de la explotación de los recursos pesqueros en servicios de financiación para apoyar la gestión

f. Apoyar las obligaciones internacionales de Ecuador en materia de pesca y ordenación de los recursos marinos.

\section{Plan maestro de estrategia comercial}

Los seis objetivos estratégicos que se han identificado, si se implementan, tienen la capacidad de orientar el crecimiento y desarrollo futuros del sector pesquero en la próxima década. Sin embargo, como se señaló anteriormente, la capacidad institucional del Ecuador y otras partes interesadas (fundamentalmente derivadas del Acuerdo Comercial Multipartes) deberá ser considerada y mejorada cuando sea apropiado y necesario para asegurar la implementación exitosa del Plan Maestro en la estrategia comercial para el sector exportador atunero, consecuente con una política pesquera sustentable y sostenible. 


\section{Tabla 2}

Plan de acción y marco lógico para abordar objetivos de estrategia comercial

Objetivo

\section{Acción requerida}

Indicadores

Verificación

estratégico

\begin{tabular}{|c|c|c|c|}
\hline \multirow[t]{6}{*}{$\begin{array}{l}\text { Implementar la gestión } \\
\text { para lograr recursos } \\
\text { pesqueros nacionales } \\
\text { sostenibles de acuerdo } \\
\text { con los principios de } \\
\text { desarrollo sustentable e } \\
\text { incluyendo, cuando } \\
\text { corresponda, la gestión de } \\
\text { la pesca basada en el } \\
\text { ecosistema. }\end{array}$} & $\begin{array}{l}\text { Desarrollar opciones de } \\
\text { política para eliminar } \\
\text { gradualmente la asignación } \\
\text { por mal tiempo y separar el } \\
\text { pago del requisito para la } \\
\text { actividad pesquera. Este } \\
\text { proyecto, se mantendrá en } \\
\text { suspenso a la espera de la } \\
\text { reforma a la política pesquera } \\
\text { enviada a la Asamblea } \\
\text { Nacional por el sector } \\
\text { exportador pesquero } \\
\text { ecuatoriano. }\end{array}$ & $\begin{array}{l}\text { Preparación de proyecto de } \\
\text { opciones de política pesquera } \\
\text { para que lo examine el } \\
\text { Gobierno. }\end{array}$ & $\begin{array}{c}\text { Disponibilidad de un } \\
\text { documento de opciones de } \\
\text { política, se han tomado } \\
\text { medidas y se ha } \\
\text { implementado un programa } \\
\text { para la eliminación gradual } \\
\text { de pesca depredadora y } \\
\text { agresiva (tanto para sectores } \\
\text { artesanales e industriales). }\end{array}$ \\
\hline & $\begin{array}{l}\text { En colaboración con las } \\
\text { partes interesadas, preparar } \\
\text { planes quinquenales de } \\
\text { gestión y desarrollo para cada } \\
\text { pesquería importante para } \\
\text { incluir la asignación de } \\
\text { recursos entre los usuarios. }\end{array}$ & $\begin{array}{c}\text { Preparación de políticas } \\
\text { públicas para el sector } \\
\text { pesquero y exportador } \\
\text { pesquero (atunero) basado en } \\
\text { los requerimientos de } \\
\text { desarrollo sustentable y } \\
\text { sostenible que demanda la } \\
\text { UE. }\end{array}$ & $\begin{array}{l}\text { Planes de gestión disponibles } \\
\text { que se utilizan para orientar } \\
\text { los arreglos de ordenación } \\
\text { pesquera para cada } \\
\text { pesquería sectorial. }\end{array}$ \\
\hline & $\begin{array}{l}\text { Investigar oportunidades de } \\
\text { ecoetiquetado para industrias } \\
\text { y pesquerías seleccionadas } \\
\text { (sector exportador atunero). }\end{array}$ & $\begin{array}{l}\text { Elaboración de informe sobre } \\
\text { oportunidades de etiquetado } \\
\text { ecológico. }\end{array}$ & $\begin{array}{c}\text { Un documento sobre } \\
\text { oportunidades de etiquetado } \\
\text { ecológico debe estar } \\
\text { disponible para su } \\
\text { consideración por la industria. }\end{array}$ \\
\hline & $\begin{array}{l}\text { Revisión de los impactos } \\
\text { económicos y ambientales de } \\
\text { las pesquerías con redes } \\
\text { como precursor de su posible } \\
\text { eliminación. }\end{array}$ & $\begin{array}{c}\text { Requisitos de pesca } \\
\text { sustentable y sostenible, de } \\
\text { acuerdo con las políticas } \\
\text { comerciales internacionales } \\
\text { de pesca actual. }\end{array}$ & $\begin{array}{l}\text { Debe estar disponible una } \\
\text { revisión de los impactos } \\
\text { económicos y ambientales de } \\
\text { las pesquerías con redes, } \\
\text { que se ha utilizado como } \\
\text { antecedentes para una } \\
\text { evaluación de políticas de } \\
\text { opciones de ordenación. }\end{array}$ \\
\hline & $\begin{array}{l}\text { Elaborar planes para una } \\
\text { licitación internacional para } \\
\text { las operaciones del nuevo } \\
\text { mercado de subasta de } \\
\text { pescado (atún), utilizando un } \\
\text { enfoque de Asociación público } \\
\text { - privada. }\end{array}$ & $\begin{array}{l}\text { Preparar ofertas, realizando } \\
\text { selección del adjudicatario. }\end{array}$ & $\begin{array}{l}\text { Identificación de adjudicatario } \\
\text { y mercado objetivo, bajo } \\
\text { gestión de asociación público } \\
\text { - privada, mixta o individual. }\end{array}$ \\
\hline & $\begin{array}{c}\text { Desarrollar una política } \\
\text { integral de desarrollo y } \\
\text { manejo de la acuicultura que }\end{array}$ & $\begin{array}{c}\text { Política sectorial } \\
\text { documentada que incluya una } \\
\text { revisión de las tarifas de la }\end{array}$ & $\begin{array}{l}\text { Disponibilidad de documento } \\
\text { de política de gestión y } \\
\text { desarrollo de la acuicultura }\end{array}$ \\
\hline
\end{tabular}




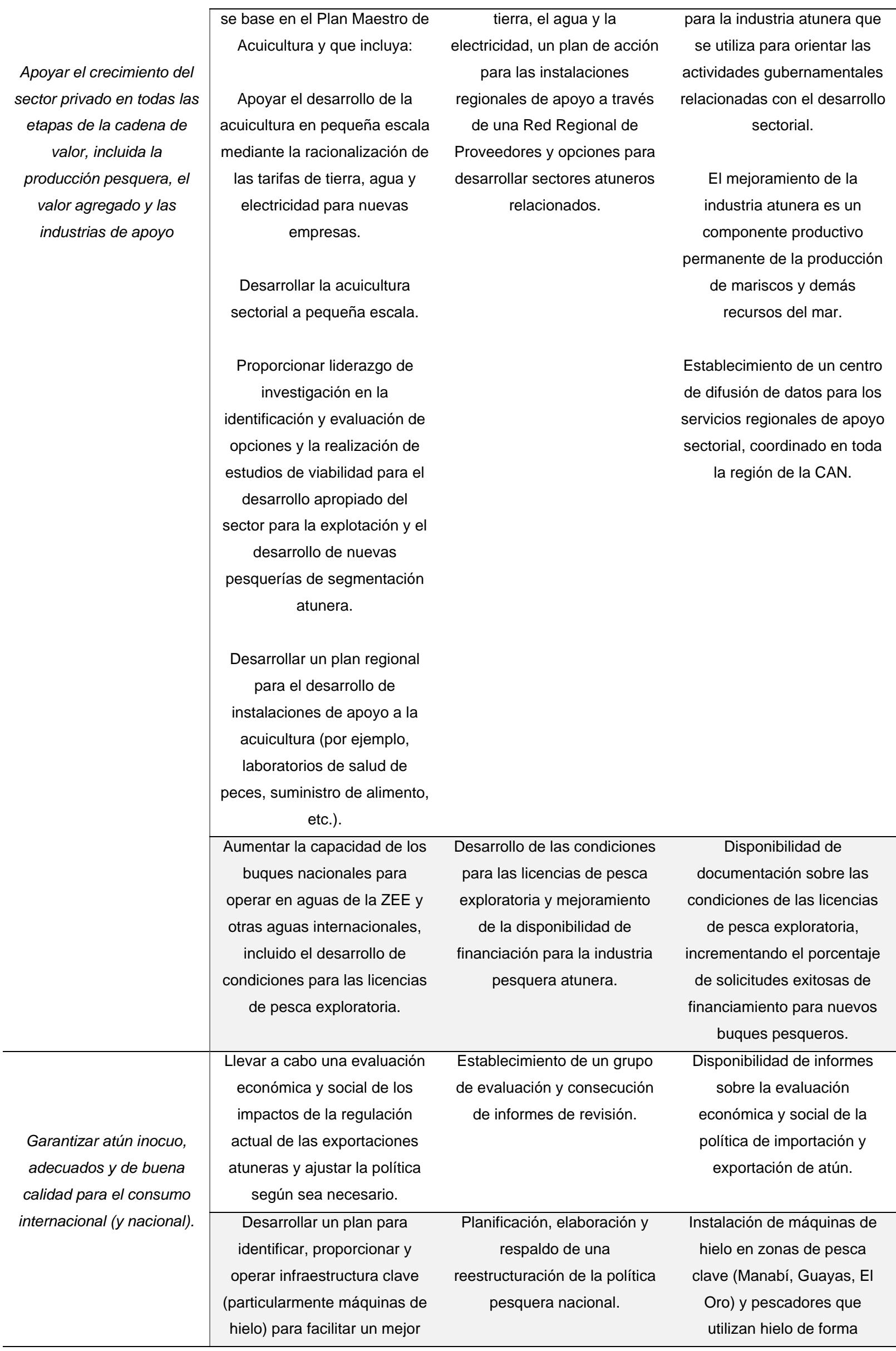




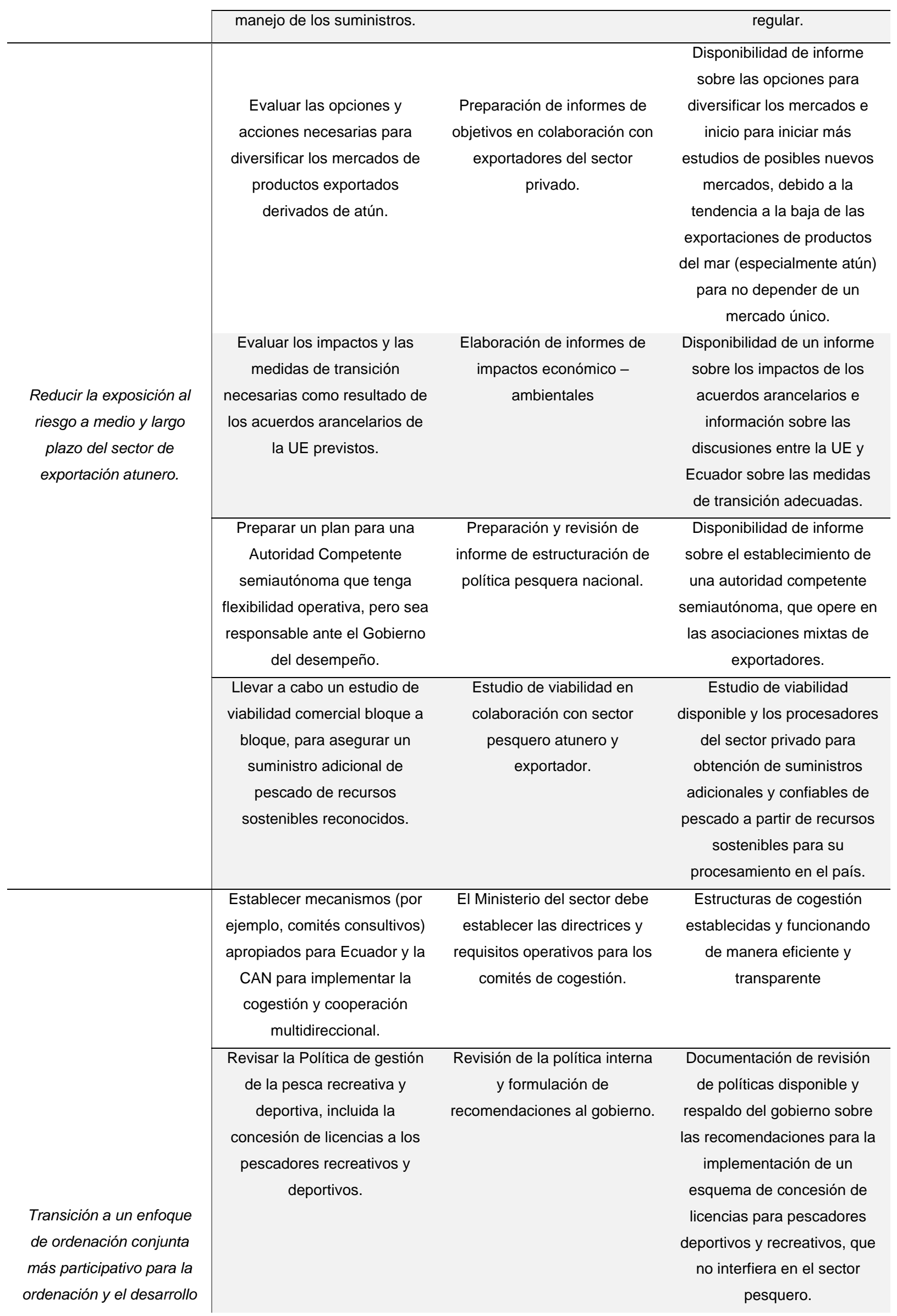




\begin{tabular}{|c|c|c|c|}
\hline \multirow[t]{2}{*}{ de la pesca. } & $\begin{array}{l}\text { En colaboración con otros } \\
\text { ministerios, examinar la } \\
\text { viabilidad y la metodología } \\
\text { para que todos los usuarios } \\
\text { de los recursos marinos } \\
\text { contribuyan a la pesca } \\
\text { sostenible y la ordenación y } \\
\text { conservación de aguas. }\end{array}$ & $\begin{array}{l}\text { Elaboración de estudios de } \\
\text { viabilidad, donde el gobierno } \\
\text { formule y examine las } \\
\text { recomendaciones. }\end{array}$ & $\begin{array}{l}\text { Disponibilidad de estudio de } \\
\text { viabilidad donde el gobierno } \\
\text { se adhiera sobre las } \\
\text { recomendaciones para la } \\
\text { reanudación de impuestos a } \\
\text { todos los usuarios de } \\
\text { recursos marinos, } \\
\text { específicamente del sector } \\
\text { exportador. }\end{array}$ \\
\hline & $\begin{array}{l}\text { Establecer un Fondo de } \\
\text { desarrollo de la pesca } \\
\text { sostenible, financiado por los } \\
\text { usuarios de los recursos } \\
\text { marinos, que incluya la fusión } \\
\text { de las funciones del Fondo de } \\
\text { Bienestar Pesquero y el } \\
\text { Fondo de Inversión de } \\
\text { Pescadores. }\end{array}$ & $\begin{array}{l}\text { Establecimiento de un fondo } \\
\text { de desarrollo de la pesca } \\
\text { sostenible, con } \\
\text { procedimientos de } \\
\text { gobernanza, personal y } \\
\text { directrices de procedimientos } \\
\text { de financiación adecuados. }\end{array}$ & $\begin{array}{l}\text { Adecuación de un fondo de } \\
\text { desarrollo, que este } \\
\text { constantemente operativo } \\
\text { para la consecución de } \\
\text { objetivos comerciales en el } \\
\text { entorno internacional. }\end{array}$ \\
\hline \multirow{3}{*}{$\begin{array}{l}\text { Apoyar las obligaciones } \\
\text { internacionales de } \\
\text { Ecuador en materia de } \\
\text { pesca y ordenación de los } \\
\text { recursos marinos. }\end{array}$} & $\begin{array}{c}\text { Evaluación de las } \\
\text { obligaciones de Ecuador en } \\
\text { relación con su membresía en } \\
\text { organizaciones marítimas } \\
\text { internacionales, incluida la } \\
\text { forma de involucrar al sector } \\
\text { privado en asuntos } \\
\text { internacionales y regionales } \\
\text { para que los planes de } \\
\text { desarrollo del sector } \\
\text { exportador estén alineados } \\
\text { con la política del gobierno. }\end{array}$ & $\begin{array}{l}\text { Consecución de evaluación } \\
\text { en colaboración del sector } \\
\text { privado exportador de atún. }\end{array}$ & $\begin{array}{c}\text { Disponibilidad de un } \\
\text { documento de evaluación } \\
\text { que se utilice para definir las } \\
\text { actividades de Ecuador en } \\
\text { las organizaciones marítimas } \\
\text { internacionales de } \\
\text { conformidad con los objetivos } \\
\text { estratégicos a largo plazo. }\end{array}$ \\
\hline & $\begin{array}{l}\text { Revisión de las tarifas y las } \\
\text { condiciones de las licencias } \\
\text { para los buques extranjeros } \\
\text { que pescan en la ZEE de } \\
\text { Ecuador para determinar si } \\
\text { siguen siendo apropiadas, } \\
\text { justas y equitativas. }\end{array}$ & $\begin{array}{l}\text { Consecución de evaluación } \\
\text { de relaciones comerciales y } \\
\text { estructuración de } \\
\text { recomendaciones al Estado. }\end{array}$ & $\begin{array}{l}\text { Documento de revisión en } \\
\text { consideración de las } \\
\text { recomendaciones basadas } \\
\text { en la estructura de tarifas de } \\
\text { licencia que deben ser } \\
\text { modificadas según sea } \\
\text { necesario. }\end{array}$ \\
\hline & $\begin{array}{l}\text { Realizar una evaluación de la } \\
\text { estructura y los costos de las } \\
\text { actuales regulaciones } \\
\text { pesqueras que inciden en el } \\
\text { comercio entre la UE y } \\
\text { Ecuador, para promover un } \\
\text { mejoramiento del Acuerdo } \\
\text { Comercial desde un enfoque } \\
\text { sustentable y sostenible, de } \\
\text { acuerdo con el comercio } \\
\text { internacional en calidad de } \\
\text { productos y mantenimiento } \\
\text { del medio marino. }\end{array}$ & $\begin{array}{l}\text { Consecución de evaluación y } \\
\text { formulación de } \\
\text { recomendaciones al } \\
\text { ministerio del sector. }\end{array}$ & $\begin{array}{c}\text { Disponibilidad de un } \\
\text { documento de evaluación } \\
\text { que sea utilizado para } \\
\text { informar al Gobierno de los } \\
\text { avances comerciales de las } \\
\text { negociaciones entre el sector } \\
\text { público - privado. }\end{array}$ \\
\hline
\end{tabular}


Nota. Tabla 2 muestra el Plan Maestro en la estrategia comercial para el sector exportador atunero.

\section{Conclusiones}

El presente estudio ha concluido con la consecución de los objetivos de investigación, donde la determinación del objetivo general analizó los beneficios que brinda el Acuerdo Comercial Multipartes para el incremento y fortalecimiento del sector exportador de atún hacia el mercado italiano, considerando que Ecuador es uno de los principales productores y exportadores de atún en el mundo.

El primer objetivo específico recopiló información sobre las causas del descenso de las exportaciones de atún a la UE, específicamente al mercado italiano, encontrando que, la primera causa se fundamentaba en la política pesquera del Ecuador que lleva falencias a toda la cadena productiva involucrada en el sector.

Asimismo, la segunda causa del descenso de las exportaciones de atún al mercado italiano, se deben principalmente a la pandemia por Covid-19, que causó que el país europeo limite sus importaciones y exportaciones, con lo que Ecuador se vio afectado en la productividad y comercialización internacional por causa de fuerza mayor en una pandemia internacional, que además desde el sector exportador atunero ecuatoriano, también se vio limitado debido al Estado de Excepción establecido mediante Decreto Ejecutivo 1017, en marzo de 2020, que causó severas aflicciones en el sector empresarial y los mercados internacionales donde el país participa.

Las características, ventajas, desventajas y experiencias que conlleva este Acuerdo Comercial Multipartes para el sector atunero nacional, se definen desde el entorno del comercio internacional que se negoció inicialmente desde las mesas de negociaciones entre la Comunidad Andina de Naciones y la Unión Europea, donde cada país de la región andina determinó su entorno comercial a conveniencia de los sectores productivos, en contraste con los países de la UE, que lo hicieron en bloque. Por ello, las ventajas que se derivaron del acuerdo se han visto vulneradas por medidas unilaterales del bloque europeo que han impuesto medidas restrictivas a las exportaciones de atún ecuatoriano, debido a falencias en los procesos y políticas pesqueras.

La propuesta de la estrategia comercial para el sector atunero, se ha establecido sobre 6 objetivos estratégicos que buscan promover el mantenimiento y desarrollo de las exportaciones hacia el mercado italiano, motivando a la coordinación y comunicación entre el Estado y los sectores exportadores y productores de atún, con lo que, la cadena de producción y comercialización se reestructuraría no solo en los procesos pesqueros, sino que además busca una política de pesca sostenible y sustentable con identidad de bloque, para el fortalecimiento de la CAN y la posición del Ecuador en el mercado internacional, y con ello, aprovechar los beneficios que brinda la vigencia del Acuerdo Comercial Multipartes. 


\section{Referencias}

Aguilar, P., Maldonado, D., \& Solorzano, S. (08 de Enero de 2019). Incidencia de la balanza comercial en el crecimiento económico del Ecuador: Análisis econométrico desde Cobb Douglas, período 1980 - 2019. Revista Espacios, 41(3), 8.

Banco Central del Ecuador. (2020). Balanza comercial del Ecuador, Sector Exportador de Atún: 2017 - 2019 Ecuador - Unión Europea (Mercado Italiano). Informe de Comercio Exterior, BCE, Quito.

Banco Central del Ecuador. (2020). Exportaciones no petroleras del Ecuador a la Unión Europea. Informe anual, BCE, Departamento de Índices Estadísticos, Quito.

Baquerizo, M. I., Barbery, C. C., \& Bocca, F. (2018). El rol del comercio internacional en el crecimiento económico del Ecuador. Antecedentes y perspectivas. Escuela Politécnica del Litoral, Programa de Maestría en Economía con Especialización en Macroeconomía. Guayaquil: ESPOL.

Basco, A. I., Beliz, G., Coatz, D., \& Garnero, P. (2018). Industria 4.0. Fabricando el futuro del comercio internacional (Tercera ed., Vol. III). Buenos Aires, Argentina: Ediciones Pasquialini.

Caballero, M. I., Bacaria, J., \& Tur, A. A. (2016). Integración comercial y crecimiento económico en América Latina. Investigación científica, Universidad Autónoma de Barcelona, Programa Doctoral en Comercio Exterior e Integración Política, Barcelona.

Cámara Nacional de la Pesquería. (2019). Exportaciones de lomos y conservas de atún . Informe anual, CNP, Guayaquill.

Cámara Nacional de Pesquería. (2019). Miembros plenos de socios exportadores de atún del Ecuador. Informe anual, CNP, Departamento de Gestión, Guayaquil.

Comisión Económica para América Latina y el Caribe. (2019). Boletín Estadístico de Comercio Exterior en América Latina y el Caribe. Informe anual, CEPAL, Departamento de Estadística, Santiago de Chile.

Comisión Económica para América Latina y el Caribe. (2019). Desarrollo económico y comercial internacional de América Latina: Vigencia del Acuerdo Comercial entre Ecuador y la Unión Europea. Informe económico de comercio internacional, CEPAL, Santiago de Chile.

Decreto Ejecutivo No. 1017. (2020). Declárese el Estado de Excepción por calamidad pública en todo el territorio nacional, por los casos de Coronavirus confirmados y la declaración de Pandemia Covid-19. Legislación Nacional. Decreto Ejecutivo, Presidencia de la República del Ecuador, Quito.

Dragún, P., Ernst, C., Díaz, F. G., \& Kübler, D. (2020). El futuro del trabajo en el mundo de la Industria 4.0. Informe de Comercio y Desarrollo Laboral Internacional, OIT, Oficina de la Organización Mundial del Trabajo en Argentina, Buenos Aires.

Federación Ecuatoriana de Exportadores. (2019). Comercio Exterior entre Ecuador y la Unión Europea, Acuerdo Comercial Multipartes. Transición 2016 - 2017, 2018. Informe anual, FEDEXPOR, Departamento de Estadística, Guayaquil. 
Fondo Monetario Internacional. (2016). La liberalización del comercio mundial y los países en desarrollo. Informe de Desarrollo Comercial Internacional, FMI, Índice Estadístico de Desarrollo Económico Mundial: América Latina, Nueva York.

Global Trade Alert. (2020). Restricciones al Comercio Exterior en el contexto internacional. América Latina. Centro de Investigación en Política Económica del Reino Unido. Londres: GTA.

Hidalgo, R. (Enero de 2018). Tendencias del Comercio Internacional de bienes, políticas comerciales y negociaciones multilaterales. (CLACSO, Ed.) Revista de Comercio Internacional del Consejo Latinoamericano de Ciencias Sociales, 159(1), 26.

Jürgensen, M. (2019). Acuerdo Comercial Multipartes Ecuador - Unión Europea. Perspectivas de desarrollo económico y crecimiento comercial a corto, mediano y largo plazo. Informe Comercial de Exportaciones-Importaciones, Consejo Económico y Comercial de la Unión Europea, Dirección General de Comercio para América Latina, Bruselas.

Ley Orgánica para el Desarrollo de la Acuicultura y Pesca. (2020). Reforma a las prácticas del sector pesquero. Exportaciones de Atún al mercado de la Unión Europea en el marco del Acuerdo Comercial. Título Preliminar, Capítulo I, Artículo 1, Objeto y 2, Ámbito de Aplicación. Informe de legislación pesquera, Asamblea Nacional del Ecuador, Comisión de Acuicultura y Pesca, Quito.

Martín, C. (Enero de 2016). Las relaciones América Latina - Unión Europea: Antecedentes de la Importancia e Institucionalización del Diálogo Político y Económico. (ANEPE, Ed.) Revista de Ciencias Económicas y Políticas de la Universidad Católica de Chile, 2(16), 32.

Ministerio de Comercio Exterior de la República del Ecuador. (2017). Acuerdo Comercial Ecuador Unión Europea. Informe de Comercio Exterior, Sección Comercial para Ecuador; Comisión Europea para Asuntos Comerciales, Quito.

Ministerio de Producción, Comercio Exterior, Inversiones y Pesca. (2019). Informe de Exportaciones del Ecuador: Balanza Comercial 2019, sector del Atún . Quito: MPCEIP.

Páez, G. (Junio de 2018). Importancia del Comercio Exterior. Acuerdo Comercial Multipartes Ecuador - Unión Europea. Revista de Economía de la Universidad San Francisco de Quito, 78(16), 42.

Rapoport, M., \& Guiñazú, S. (2016). Raúl Prebisch: Historia, pensamiento y vigencia de la teoría de la transformación para el desarrollo de América Latina. Artículo científico, Universidad de Buenos Aires, Centro de Estudios Económicos y Empresariales, Buenos Aires.

Rivadeneira, K. H., Iturriaga, S. M., \& Andrade, E. A. (2019). Acuerdo Multipartes entre la Unión Europea y Ecuador: Análisis del Impacto en la Asociación de Comercialización y Exportación del sector Pesquero en los años 2017 - 2018. Pontificia Universidad Católica del Ecuador, Sistema de Posgrados. Escuela de Negocios Internacionales. Quito: PUCE.

Rosales, D. E., \& Guerrero, L. A. (2019). Los primeros 18 meses del Acuerdo Multipartes EcuadorUnión Europea. Universidad San Francisco de Quito, Programa de Maestría en Comercio Internacional. Quito: USFQ.

Rosales, O., \& Herreros, S. (Marzo de 2017). Desafíos de la competitividad exportadora en América Latina y el Caribe. Revista de Estudios Internacionales del Instituto de Estudios de Comercio Exterior de la Universidad de Chile, 26(12), 136. 
Ruano, L. (Abril de 2018). La Unión Europea y América Latina y el Caribe: Breve historia de la relación económica birregional. Revista Mexicana de Política Exterior, 112(27), 21.

Ruas, O. O. (2016). Metodología de la Investigación científica para desarrollo de mercado en negocios internacionales. Universidad Complutense de Madrid, Departamento de Investigación en Economía y Finanzas. Especialización en Comercio Internacional. Madrid: UCM.

Savignat, A.-S. (Julio de 2015). Raúl Prebisch: del ciclo económico al desarrollo económico. Revista Ciclos de la Universidad de Cergy, XV(29), 74.

Tamayo, R. A., \& Vásquez, J. I. (2019). El Acuerdo Comercial de Ecuador con la Unión Europea y el comportamiento de las Exportaciones ecuatorianas. Universidad Andina Simón Bolívar, Programa de Maestría en Gestión Comercial. Quito: UASB.

Villegas, D. M., Montesdeoca, E. A., \& Conde, R. D. (Enero de 2018). Relación Estratégica para el Desarrollo del Ecuador. Acuerdo Comercial Multipartes con la Unión Europea. (PUCE, Ed.) Revista de Economía y Política de la Pontificia Universidad Católica del Ecuador, 10(3), 168. 